\title{
Effect of Reinforcement of Hydrophobic Grade Banana (Musa ornata) Bark Fiber on the Physicomechanical Properties of Isotactic Polypropylene
}

\author{
Md. Mamunur Rashid, ${ }^{1}$ Sabrin A. Samad, ${ }^{1}$ M. A. Gafur, ${ }^{2}$ \\ Md. Rakibul Qadir, ${ }^{2}$ and A. M. Sarwaruddin Chowdhury ${ }^{1}$ \\ ${ }^{1}$ Department of Applied Chemistry and Chemical Engineering, Faculty of Engineering and Technology, \\ University of Dhaka, Dhaka 1000, Bangladesh \\ ${ }^{2}$ Pilot Plant and Process Development Center (PP \& PDC), Bangladesh Council of Scientific and Industrial Research, \\ Dhaka 1205, Bangladesh
}

Correspondence should be addressed to Sabrin A. Samad; sabrinsamad@duet.ac.bd

Received 28 December 2015; Revised 15 March 2016; Accepted 4 April 2016

Academic Editor: Matheus Poletto

Copyright (C) 2016 Md. Mamunur Rashid et al. This is an open access article distributed under the Creative Commons Attribution License, which permits unrestricted use, distribution, and reproduction in any medium, provided the original work is properly cited.

\begin{abstract}
This research studied the physicomechanical as well as morphological properties of alkali treated $\left(\mathrm{NaOH}\right.$ and $\left.\mathrm{KMnO}_{4}\right)$ and untreated banana bark fiber (BBF) reinforced polypropylene composites. A detailed structural and morphological characterization was performed using Fourier transform infrared spectroscopy (FTIR), scanning electron microscopy (SEM), and mechanical properties testing (tensile strength, flexural strength, and microhardness). Chemical treatments improved the hydrophobic property of the fiber and it is found to be better for $\mathrm{KMnO}_{4}$ treatment. Composites with 0, 5, 10, and $15 \mathrm{wt}$ \% loadings were then compared for water uptake studies and revealed that $\mathrm{KMnO}_{4}$ treated fiber composites absorb less water compared to others. $\mathrm{KMnO}_{4}$ treatment with $15 \%$ fiber loading improved the tensile strength, flexural strength, and microhardness of the composites compared to raw and $\mathrm{NaOH}$ treated fiber loadings. TGA analysis also shows onset temperature at $400 \sim 500^{\circ} \mathrm{C}$ that is associated with the decomposition of the banana fibers constituents including lignin, cellulose, and hemicelluloses which suggests better thermomechanical stability. All of the values suggest that $15 \% \mathrm{KMnO}_{4}$ treated banana bark fiber $(\mathrm{BBF}) / \mathrm{PP}$ composites were found to be better than those of the raw and $\mathrm{NaOH}$ treated ones.
\end{abstract}

\section{Introduction}

In recent years, the use of composite materials has increased too manyfold. The reason behind that is their versatile use, ease of preparation, eco-friendly system, improved mechanical and usable properties, and low cost. One of widely used composite materials is composed of polymeric matrix. These polymer matrixes are often reinforced with synthetic (glass fiber, carbon, and aramid) and natural fibers (sisal, jute, flax, etc.). These polymer matrix composites (PMCs) are not only used in industries, automobiles, ships, and structural applications but also proved to be advantageous for their high strength to weight ratio, ease to fabricate, complex shapes, low cost, and good resistance to corrosion and marine fouling $[1,2]$. Synthetic fiber based composites are less prone to degradation because of their high molecular mass and hydrophobic character. Natural fiber reinforced composites show few drawbacks like low strength, poor interfacial bonding, and moisture uptake compared to artificial fiber reinforced composites. Natural fibers are particularly sensitive to moisture because fiber/matrix interface is critical zone for composite long-term performance [3]. Chemical treatment is an essential processing parameter to reduce hydrophilic nature of the fibers and thus improves adhesion with the matrix. Pretreatments of fiber change its structure and surface morphology. Hydrophilic hydroxyl groups are removed from the fiber by the action of different chemicals. Significant improvements in the mechanical properties of the composites are reported by using different chemical treatments $\left(\mathrm{NaOH}, \mathrm{KMnO}_{4}\right.$, etc.) to achieve a good adhesion 
between fiber and matrix [4]. After these treatments of fibers, removal of hemicelluloses, pectin, lignin, and wax and increases in roughness of fibers were observed [4] in addition to mechanical interlocking [5]. Chemically treated fiber reinforced composites show significant improvement in mechanical properties [6]. Studies have shown that $\mathrm{NaOH}$ treated coir fiber had better mechanical property than sodium lauryl sulphate (SLS) treated coir fiber. In both cases the fiber was reinforced with epoxy resin [7]. Results have shown that $\mathrm{NaOH}$ treated sisal fiber reinforced composites showed improved tensile and flexural strength compared to untreated sisal fiber reinforced composites [8]. Permanganate treatment on natural fibers is conducted by potassium permanganate $\left(\mathrm{KMnO}_{4}\right)$ in acetone solution. This treatment enhances chemical interlocking at the interface and provides better adhesion with the matrix (Akash et al. [9]). It also reacts with the lignin (hydrophilic $\mathrm{AOH}$ groups) constituents and separates from the fiber cell wall which causes reduction of hydrophilic nature of the fiber [10].

In Bangladesh, banana is abundantly cultivated. Banana fiber can be easily obtained from the pseudostem after the fruits and leaves are utilized and also the bark of the plant itself. Like other natural fibers such as jute, sisal, and hemp, banana fibers have also been used as a reinforcing material. Venkateshwaran et al. [11-13] studied the mechanical properties of tensile and flexural strength and impact and water absorption tests were carried out using banana/epoxy composite material. The effect of alkali and SLS (sodium lauryl sulphate) treatment on banana/kenaf hybrid composites and woven hybrid composites was also studied.

Current research activities have shifted towards the development of "cost-performance" rather than "highperformance" thermoplastic composites. Since costeffectiveness depends also on raw material cost, most composite systems that are considered as an attractive candidate for this "cost-performance" market are based on E-glass fibers and resins such as polypropylene (PP), polyamide-6,6 (PA-6,6), poly(ethylene terephthalate) (PET), or poly(butylene terephthalate) (PBT) [14]. Among these $\mathrm{PP}$ offers a number of favorable characteristics as matrix material for high volume applications of composite materials. It exhibits many beneficial properties such as low price, high toughness, low density, relatively high thermal stability, good (di) electrical properties, and chemical resistance [15]. Moreover, PP can easily be processed and recycled and is available in a large number of grades. Considering all these facts, we aimed to prepare a composite based on PP which is reinforced by chemically treated banana fiber. The aim of chemical treatment is to improve the hydrophobic character of the fiber and to afford a better reinforcement in between the fiber and hydrophobic matrix.

\section{Materials and Methods}

2.1. Preparation of Banana Fiber. Banana fibers were collected from the bark of banana plant of species Musa ornata (Sagor Kala) from Curzon Hall area. The fibers were about $30 \mathrm{~cm}$ long. When banana plants got matured, the bark of the plant was cut down into small pieces and separated layers were tied up in bundles. The bundles were put under fresh water in two separate buckets for twenty days. Then compost fertilizer was mixed with the water and bundles were kept for five more days. When rotten, the barks were taken out of the bucket and washed thoroughly with water several times and dried in open air without exposure to sunlight. The removal of impurities such as dirty materials and gummy substances was carried out by immersing dry fibers in a solution of $6.5 \mathrm{~g}$ detergent per liter of water at $70-75^{\circ} \mathrm{C}$ for $30 \mathrm{~min}$ in a beaker. Fiber-to-solution ratio was 1:50 (by weight). They were washed thoroughly with distilled water to remove impurities and dried in an oven at $50^{\circ} \mathrm{C}$ for $20 \mathrm{~min}$ before drying in open air for $24 \mathrm{hrs}$ and stored in a desiccator.

\subsection{Removal of Moisture from Treated and Untreated Banana} Fiber. Treated and untreated banana fibers were kept at $50^{\circ} \mathrm{C}$ for three hours in the oven for the removal of moisture. This was done for better sample preparation and removal of undesirable bubble in the composite. Raw BBF, $0.055 \%$ $\mathrm{KMnO}_{4}$ treated $\mathrm{BBF}$, and $7.5 \% \mathrm{NaOH}$ treated $\mathrm{BBF}$ were used to prepare $\mathrm{BBF} / \mathrm{PP}$ composites in different composition.

\subsection{Removal of Moisture from Polypropylene. Commercial} polypropylene used for the preparation of composite was isotactic and had an intermediate level of crystallinity between that of low-density polyethylene (LDPE) and that of highdensity polyethylene (HDPE). The commercial isotactic PP had a melting point that ranges from 160 to $166^{\circ} \mathrm{C}$. It was dried by desiccating the polymer in the furnace operated electrically at $80^{\circ} \mathrm{C}$ for 3 hours, for better sample preparation. Desiccating is the process of preservation by removing all water and liquids from the substance. Moisture removal of polymer was needed to make sure that the final sample was free from undesirable bubble.

2.4. Composite Pellets Preparation. PP and BBF powder were proportionately, gradually, and simultaneously poured into the hopper of an extruder set at a temperature of $170^{\circ} \mathrm{C}$. The mixture then came into the contact of header and rotating shaft, where PP melted and the speed of the shaft helped to squeeze out the mixture through nozzle. Shaft speed was kept moderate to prevent the running out of the mixture. Mixing was the major part for the extrusion. If the mixing of fiber and matrix is not done homogeneously, the quality of the products obtained would be very poor. Noodles obtained through nozzles then chopped into small pellets, which were favorable for further extrusion. This process was repeated at least three times for uniform mixing.

2.5. Composite Sheet Preparation. Beads of BBF/PP composites made by chopping the extruder's nozzle discharge were taken into a mold prepared before by polishing with very fine emery paper, acetone washing, and spraying mold releaser. Then $20 \mathrm{~g}$ of pellet was taken into a mold placed between the two steel plates of weber-pressure hydraulic press (hot press) to make composite sheet. The temperature of the hot press was set at $170^{\circ} \mathrm{C}$ while the initial pressure was set at $350 \mathrm{KN}$. 
TABLE 1: Composition of different composites.

\begin{tabular}{lcc}
\hline Composites & \multicolumn{2}{c}{ Composition (wt.\%) } \\
& PP (wt.\%) & Banana fiber (wt.\%) \\
\hline C1 & 100 & 0 \\
C2 & 95 & 5 \\
C3 & 90 & 10 \\
C4 & 85 & 15 \\
\hline
\end{tabular}

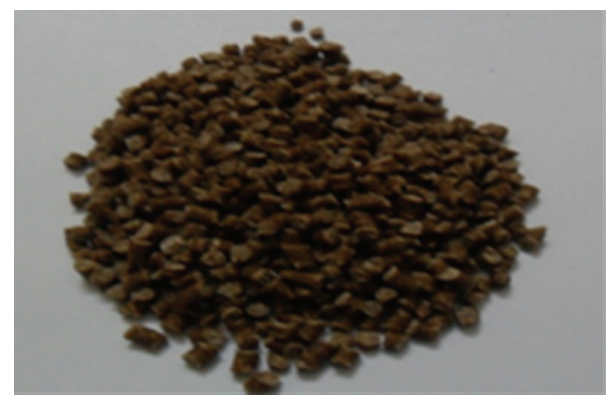

Figure 1: Pellets of BBF/PP composites.

It took around 30 minutes to reach the set temperature. After reaching the set temperature, the melt was held for about 5 minutes at $100 \mathrm{KN}$ pressure. Then the sheet was cooled down to below $40^{\circ} \mathrm{C}$ (Figures 1 and 2 and Table 1 ).

\section{Results and Discussions}

3.1. Physical Properties of Raw and Treated BBF/PP Composites. From Figure 3, it is observed that the highest value of water absorption is for $15 \%$ raw BBF/PP composites and water absorption increases with the increase of percentage of raw fiber addition. Fiber is the hydrophilic part while PP is the hydrophobic part of the composite. That is why the hydrophilicity of the composite increases with the increase of fiber percentage in the composite. The same property is also found for $\mathrm{NaOH}$ and $\mathrm{KMnO}_{4}$ treated fibers. It is also found that raw $\mathrm{BBF} / \mathrm{PP}$ composites absorb more water than treated $\mathrm{BBF} / \mathrm{PP}$ composites. Sodium hydroxide treatment removes the hydrogen bonding in the network structure of the fibers cellulose, increasing fibers surface roughness [16]. It is due to the fact that chemical treatment causes loss of hemicellulose, lignin, and pectin of the fiber, decreasing the hydrophilicity and increasing the surface tension and roughness of the fiber, ensuring proper adhesion between matrix and fiber, and making the composite less penetrable to water [17].

\subsection{Mechanical Properties of Raw and Treated BBF/PP Composites}

3.2.1. Ultimate Tensile Strength (UTS) of Raw and Treated $B B F / P P$ Composites. Tensile specimen was prepared according to ASTM D638-98. The test speed was $1 \mathrm{~mm} / \mathrm{min}$ while the number of test specimens examined is 6 . It is observed that UTS increases with fiber treatment and with the increase of percentage of fiber addition [16]. Chemical treatment of fiber reduces incompatibility between hydrophilic fiber and

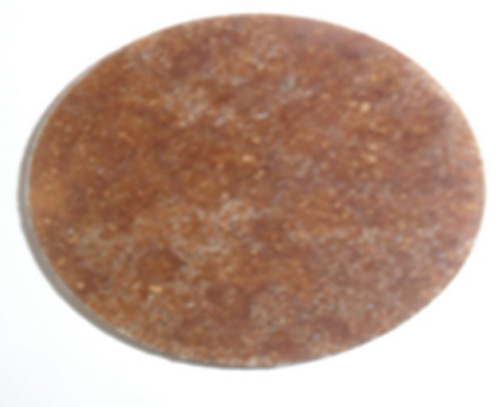

FIGURE 2: BBF/PP composites in pressed form.

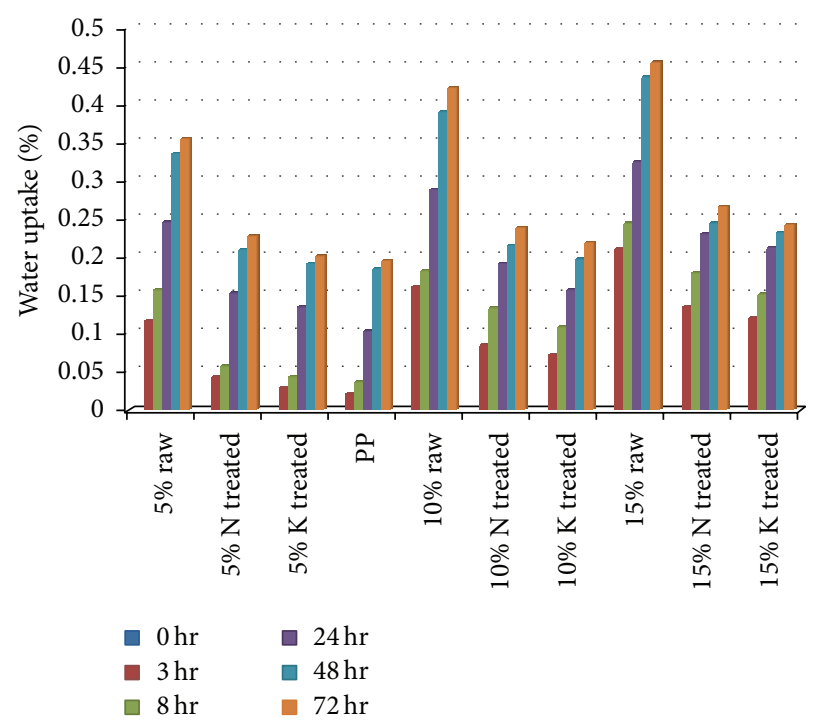

FIGURE 3: Water uptake for treated and untreated BBF/PP composites for time interval $0 \sim 72 \mathrm{hr}$.

hydrophobic PP by removing waxes and other noncellulosic substances, which brings about poor adhesion between fiber and matrix, producing rough surfaces and creating strong adhesion between matrix and fiber. With the increase of fiber addition, surface area between fiber and matrix was increased, strengthening the fiber-matrix adhesion [18]. The value of UTS for $15 \% \mathrm{KMnO}_{4}$ treated $\mathrm{BBF} / \mathrm{PP}$ composite is $35.72 \mathrm{MPa}$, which is the highest. It justifies the vigor of permanganate treatment producing the rougher surface of fiber. Thus it produces better adhesion between fiber and matrix (Figure 4).

It is also observed that $\mathrm{NaOH}$ treated $\mathrm{BBF} / \mathrm{PP}$ composites have less tensile strength with respect to $\mathrm{KMnO}_{4}$ treated $\mathrm{BBF} / \mathrm{PP}$ composites, indicating the efficiency of $\mathrm{KMnO}_{4}$ treatment over $\mathrm{NaOH}$ treatment. Permanganate treatment brings about the formation of cellulose radical through $\mathrm{Mno}^{-3}$ ion formation. The highly reactive $\mathrm{Mn}^{3+}$ is responsible for initiating permanganate induced grafting [19]. However, mechanical interlocking in permanganate treatment, between the rougher fiber and the matrix, is a predominant interfacial bonding mechanism compared to that of the chemical bonding [20]. 


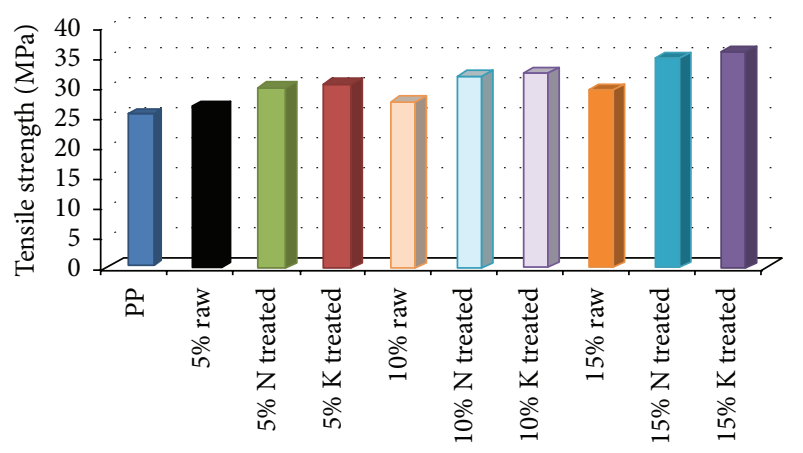

FIGURE 4: The ultimate tensile strength (UTS) of different percentages of raw and treated BBF/PP composites.

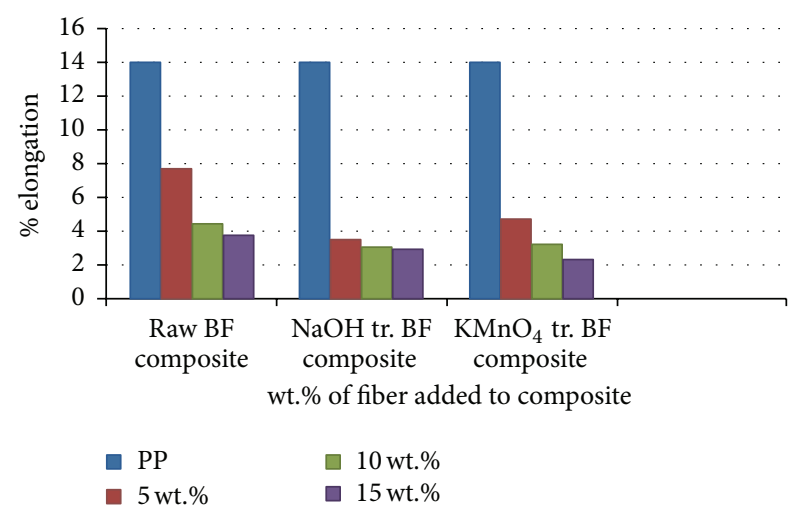

FIgURE 5: Comparison of \% elongation of raw and treated BBF/PP composites.

\subsubsection{Percentage Elongation of Raw and Treated BBF/PP} Composites. Figure 5 shows the comparison of percentage elongation of raw and treated $\mathrm{BBF} / \mathrm{PP}$ composites. It is observed that treated fiber composites have less percentage elongation than that of raw fiber reinforced composite. Chemical treatment removes lignin, hemicellulose, and other materials from the fiber. Thus roughness of the fiber surface and adhesion between matrix and fiber increased. Increased adhesion decreases ductility or increases hardness of the composites. That is why chemical treatment eventually results in less \% elongation in composites. Also $\mathrm{NaOH}$ treated fiber composite has comparatively more elongation than that of $\mathrm{KMnO}_{4}$ treated fiber composite. This is due to the more adhesion between fiber and matrix in $\mathrm{KMnO}_{4}$ treated fiber composite. As $\mathrm{KMnO}_{4}$ treatment is more vigorous than $\mathrm{NaOH}$ treatment, $\mathrm{KMnO}_{4}$ treatment removes more fiber surface material and makes the surface rougher, resulting in increased adhesion. With the increase of fiber addition, adhesion between fiber and matrix also increases because of the increase of rough surface area. So \% elongation decreases with fiber addition.

\subsubsection{Flexural Strength of Raw and Treated BF/PP Composites.} Figure 6 shows comparison of flexural strength of various percentage raw and treated $\mathrm{BBF} / \mathrm{PP}$ composites. It is observed that the highest flexural strength $(50 \mathrm{MPa})$ is for $\mathrm{KMnO}_{4}$ treated $15 \mathrm{wt} . \% \mathrm{BBF} / \mathrm{PP}$ composites and the lowest flexural

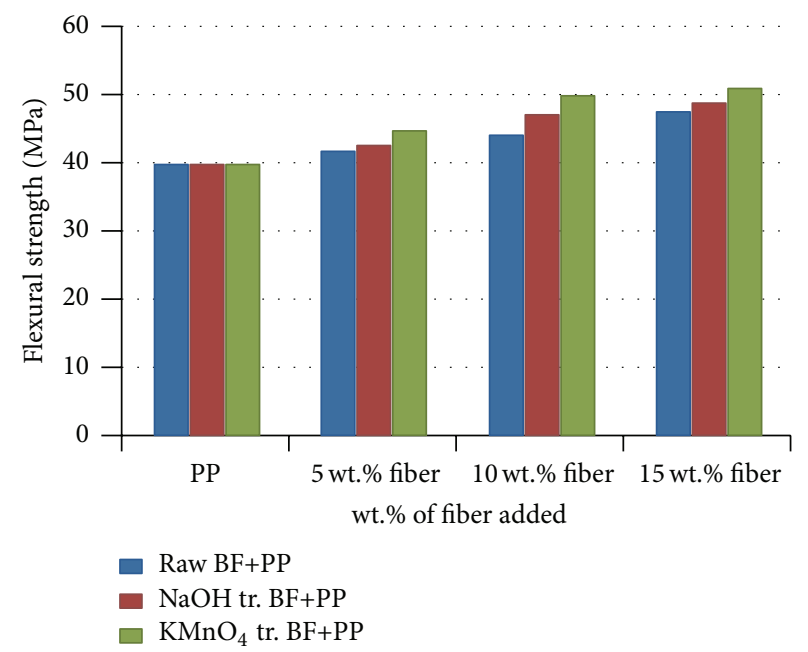

FIGURE 6: Comparison of flexural strength of different BBF/PP composites.

strength is for PP (40 MPa). Flexural strength increases with the increase of percentage of fiber addition. Goriparthi et al. [21] attributed to the fiber surface modification by both permanganate and mercerization chemical treatments for the increase of flexural strength. Because both chemical treatment and fiber content increase the adhesion forces between fiber and matrix, the highest value explains the vigor of $\mathrm{KMnO}_{4}$ treatment.

3.3. TG Analysis of BF/PP Composites. Thermal analysis is an important and very useful method to characterize any material such as thermoplastic or thermosetting polymer matrix and also to determine the influence of natural fibers addition into the polymers [22]. Thermal analysis is used as an analytical method in understanding the structural property relationship and thermal stability of composite materials, such as the incompatibility between fibers and polymer matrixes. The majority of natural fibers have low degradation temperatures $\left(200^{\circ} \mathrm{C}\right)$ as a function of cellulose and lignin which make them inadequate for processing temperatures above $200^{\circ} \mathrm{C}$ [23]. In Figure 7, S4 (red line) represents TG analysis of $\mathrm{KMnO}_{4}$ treated $15 \mathrm{wt} . \% \mathrm{BF} / \mathrm{PP}$ composite, S1 (green line) untreated $15 \mathrm{wt} . \% \mathrm{BF} / \mathrm{PP}$ composite, and S2 (blue line) $\mathrm{NaOH}$ treated 15 wt.\% BF/PP composite. From Figure 7 , it is observable that initial drop in weight is normally attributed to the release of absorbed moisture or the vaporization of water related to the humidity from the surface of fibers. The interaction between hydrogen bonds allowed the thermal energy to be distributed over many bonds and is a major source of stability in cellulose [24]. This was correlated with the dehydration of the banana fiber. After the first constant stage, a sloping decrease in weight occurred until the onset temperature reached at $400 \sim 500^{\circ} \mathrm{C}$. This sloping decrease can be associated with the decomposition of the banana fibers constituents including lignin, cellulose, and hemicelluloses. The higher onset temperature means the higher crystallinity and stability [25]. So from the figure it is 


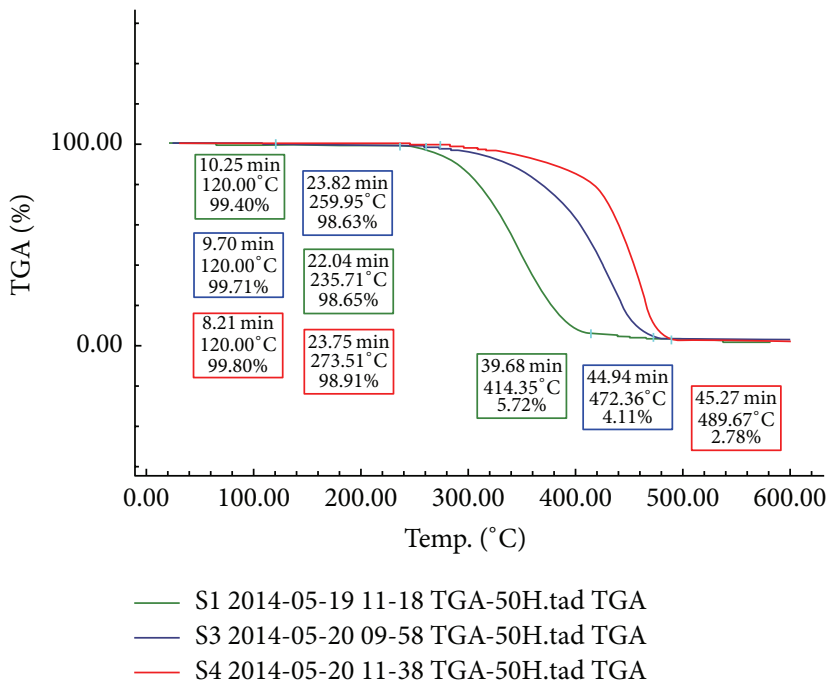

Figure 7: TGA analysis for different BBF/PP composites. Thermal analysis result, Center for Advanced Research in Sciences, University of Dhaka.

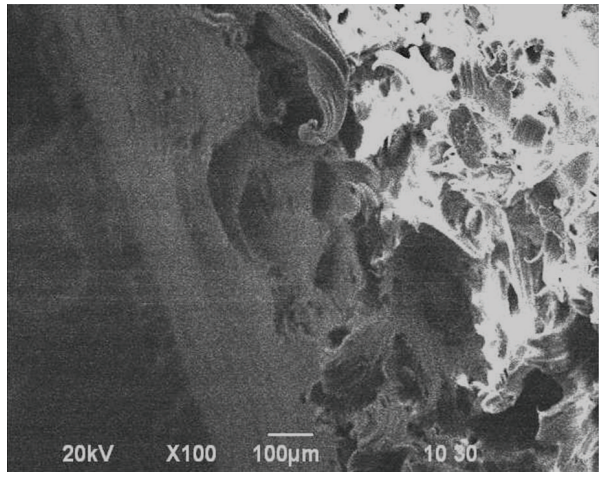

(a)

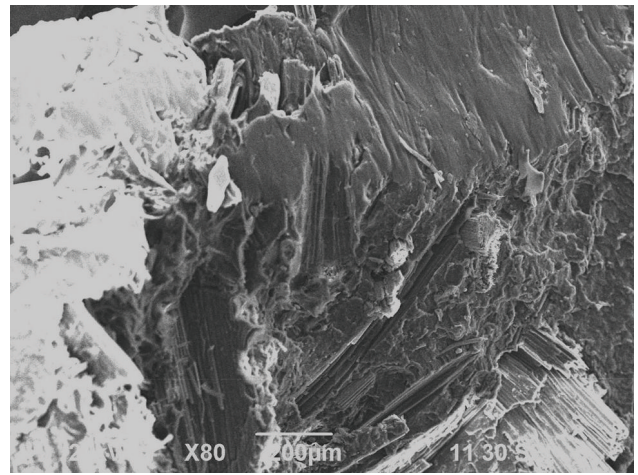

(b)

FIGURE 8: SEM images of tensile fractured surfaces of (a) $\mathrm{NaOH}$ treated composites and (b) untreated composites.

clear that $\mathrm{KMnO}_{4}$ treated 15 wt.\% $\mathrm{BF} / \mathrm{PP}$ composite has the highest crystallinity and thermal stability. The lowest water absorption by this composite also justifies the fact.

3.4. SEM Analysis of BBF/PP Composites. SEM images of tensile fractured surfaces of untreated and $\mathrm{NaOH}$ treated composites are shown in Figure 8. The fractured surface of untreated banana fiber composite exhibits a large number of pullouts, indicating poor fiber-matrix adhesion. It can also be observed from Figure 8(b) that no matrix is adhered to the surface of pulled out fiber, indicating the incompatibility between matrix and fiber. On the other hand, $\mathrm{NaOH}$ treated composite exhibits a fiber breakage rather than pullout that indicates a strong interfacial bonding between the fiber and matrix, which in turn results in the transfer of stress between the fiber and the matrix [21].

3.5. FTIR Analysis. Figure 9(a) shows the FTIR spectrum of PP. From the figure, $\mathrm{C}-\mathrm{H}$ asymmetric stretching band at $2929 \mathrm{~cm}^{-1}$ and $\mathrm{C}-\mathrm{H}$ asymmetric deformation band at $1454 \mathrm{~cm}^{-1}$ for $\mathrm{CH}_{2}$ and $\mathrm{CH}_{3}$ group, respectively, and $\mathrm{C}-\mathrm{C}$ absorption band at $1200 \sim 1000 \mathrm{~cm}^{-1}$ for carbon chain are observed. Figure 9(b) shows the FTIR spectrum of $15 \%$ raw $\mathrm{BBF} / \mathrm{PP}$ composite. From the figure, it can be noted that there is an absorption peak at $3340 \mathrm{~cm}^{-1}$ indicating $\mathrm{O}-\mathrm{H}$ stretching absorption band. Here, $\mathrm{C}-\mathrm{H}$ asymmetric stretching band at $2927 \mathrm{~cm}^{-1}$ and $\mathrm{C}-\mathrm{H}$ asymmetric deformation band at $1452 \mathrm{~cm}^{-1}$ for $\mathrm{CH}_{2}$ and $\mathrm{CH}_{3}$ group, respectively, $\mathrm{C}=\mathrm{C}$ stretching band at $1641 \mathrm{~cm}^{-1}, \mathrm{C}-\mathrm{O}$ absorption band at $1226 \mathrm{~cm}^{-1}$ for ether group and C-O absorption band at $1035 \mathrm{~cm}^{-1}$ for primary hydroxyl group, and C-C absorption band at 1200 $1000 \mathrm{~cm}^{-1}$ for carbon chain are observed.

Figures 10(a) and 10(b) show the FTIR spectrum of $15 \%$ treated BF/PP composites. From the figure, it can be noted that there is an absorption peak at $3307 \mathrm{~cm}^{-1}$, which indicates $\mathrm{O}-\mathrm{H}$ stretching absorption band. Here, C-H asymmetric stretching band at $2927 \mathrm{~cm}^{-1}$ and C-H asymmetric deformation band at $1450 \mathrm{~cm}^{-1}$ for $\mathrm{CH}_{2}$ and $\mathrm{CH}_{3}$ group, respectively, $\mathrm{C}=\mathrm{C}$ stretching band at $1641 \mathrm{~cm}^{-1}, \mathrm{C}-\mathrm{O}$ absorption band at $1224 \mathrm{~cm}^{-1}$ for ether group, and C-C absorption band at $1200 \sim 1000 \mathrm{~cm}^{-1}$ for carbon chain are seen. Sgriccia et al. [26] 


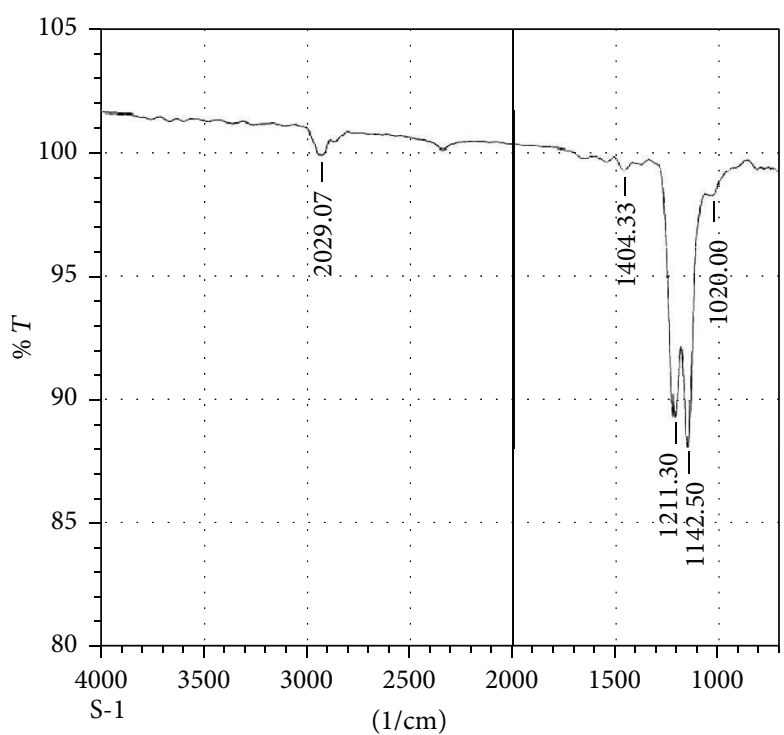

(a)

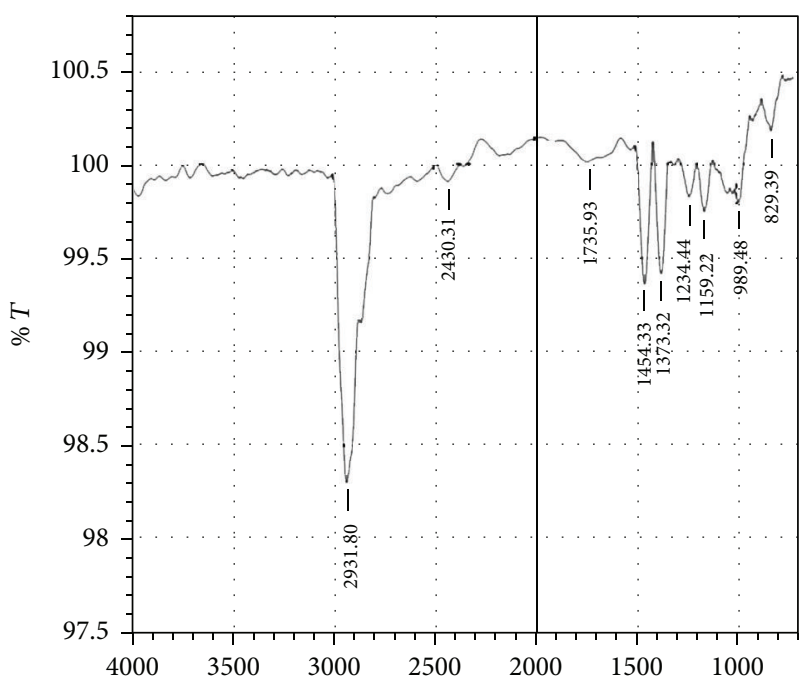

(b)

FIGURE 9: (a) FTIR spectrum of PP and (b) FTIR spectrum of 15\% raw BBF/PP composite.

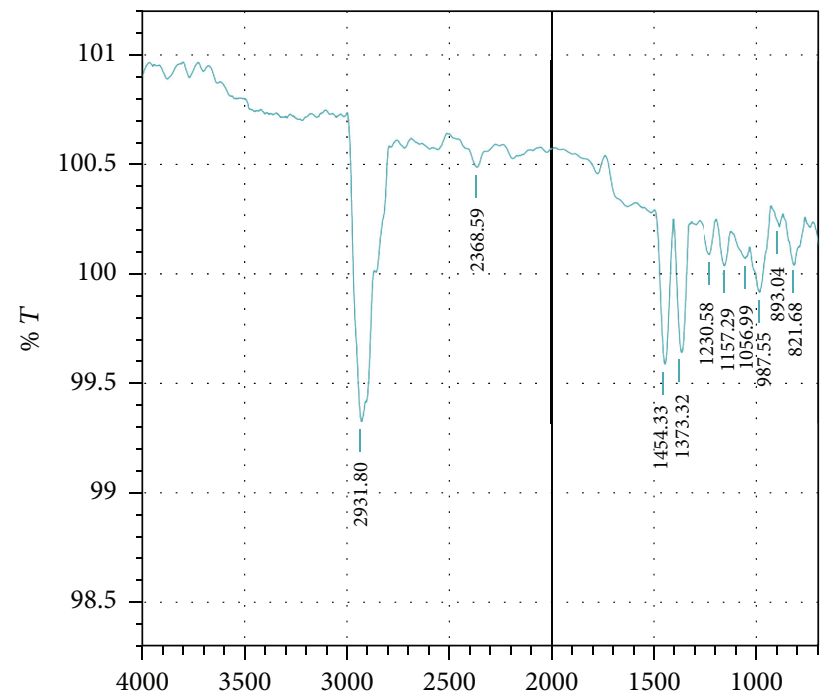

(a)

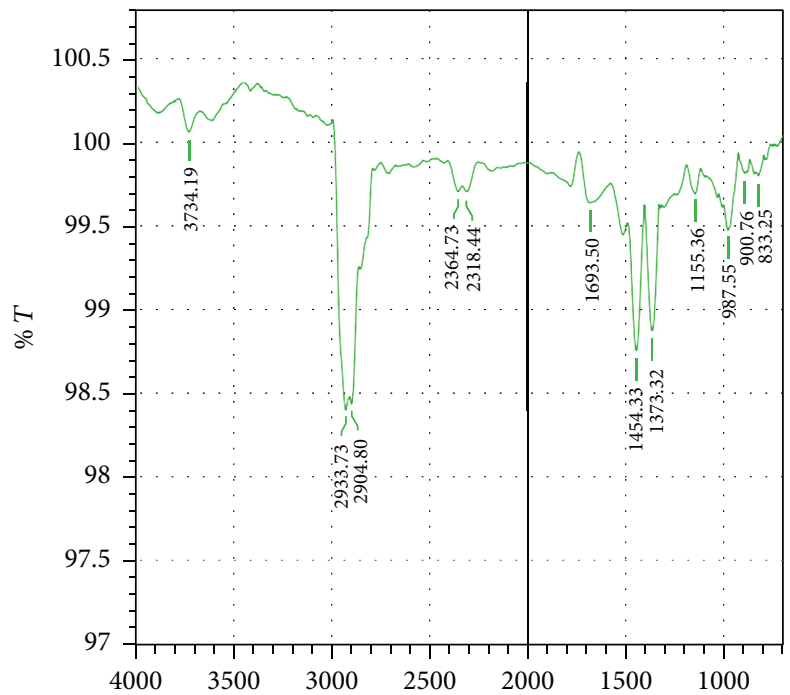

(b)

Figure 10: (a) FTIR spectrum of $15 \% \mathrm{NaOH}$ treated $\mathrm{BF} / \mathrm{PP}$ and (b) $15 \% \mathrm{KMnO}_{4}$ treated $\mathrm{BBF} / \mathrm{PP}$ composites.

studied the effects of $\mathrm{NaOH}$ fiber treatment on the natural fiber surfaces using FTIR. They attributed the disappearance of $\mathrm{C}=\mathrm{O}$ stretching of the acetyl group of hemicellulose to the removal of hemicellulose from the fiber surfaces. From Figure 9(b), it can be seen that $1735 \mathrm{~cm}^{-1}$ peak for $\mathrm{C}=\mathrm{O}$ stretching of the acetyl group of hemicellulose is present in raw banana fiber [27, 28]. But from Figures 10(a) and 10 (b) this is evident that this peak is disappeared from both alkali and $\mathrm{KMnO}_{4}$ treated $\mathrm{BBF} / \mathrm{PP}$ composite samples, which proves that both fiber treatments cause the removal of hemicellulose [28]. Again, $1234 \mathrm{~cm}^{-1}$ peak for $\mathrm{C}=\mathrm{O}$ stretching of the acetyl group of lignin is not present in the $\mathrm{KMnO}_{4}$ treated BBF/PP composite sample (Figure 10(b)), which means that $\mathrm{KMnO}_{4}$ treatment removes lignin from the fiber.
But this peak is reduced to $1230 \mathrm{~cm}^{-1}$ and is less intense in case of alkali treated BBF/PP composite sample, which means that alkali treatment partially removed lignin from the fiber [28].

\section{Conclusions}

In this study, we have prepared composites using treated and untreated banana fibers with commercial PP as a matrix. The water uptake studies reveal that $5 \% \mathrm{KMnO}_{4}$ treated fiber composites absorb less water compared to others. The mechanical property of $\mathrm{KMnO}_{4}$ treated composite appears to be better in terms of ultimate tensile strength $(25 \mathrm{MPa})$, flexural strength (50 MPa), and microhardness. TGA analysis 
shows onset temperature at $400 \sim 500^{\circ} \mathrm{C}$ that can be associated with the decomposition of the banana fibers constituents including lignin, cellulose, and hemicelluloses. In conclusion, chemically treated banana bark fiber (BBF) has the capability to improve the composite properties, which is attributed to better hydrophobic character accompanied with better mechanical properties as well as less water adsorption for the fiber reinforced commercial PP composite.

\section{Competing Interests}

The authors declare that they have no competing interests.

\section{References}

[1] L. Yan, N. Chouw, and K. Jayaraman, "Flax fibre and its composites-a review," Composites Part B: Engineering, vol. 56, pp. 296-317, 2014.

[2] I. Pillin, A. Kervoelen, A. Bourmaud, J. Goimard, N. Montrelay, and C. Baley, "Could oleaginous flax fibers be used as reinforcement for polymers?" Industrial Crops and Products, vol. 34, no. 3, pp. 1556-1563, 2011.

[3] A. Le Duigou, P. Davies, and C. Baley, "Exploring durability of interfaces in flax fibre/epoxy micro-composites," Composites Part A: Applied Science and Manufacturing, vol. 48, no. 1, pp. 121-128, 2013

[4] M. M. Kabir, H. Wang, K. T. Lau, and F. Cardona, "Chemical treatments on plant-based natural fibre reinforced polymer composites: an overview," Composites Part B: Engineering, vol. 43, no. 7, pp. 2883-2892, 2012.

[5] Y. Li, K. L. Pickering, and R. L. Farrell, "Analysis of green hemp fibre reinforced composites using bag retting and white rot fungal treatments," Industrial Crops and Products, vol. 29, no. 2-3, pp. 420-426, 2009.

[6] D. Sedan, C. Pagnoux, A. Smith, and T. Chotard, "Mechanical properties of hemp fibre reinforced cement: influence of the fibre/matrix interaction," Journal of the European Ceramic Society, vol. 28, no. 1, pp. 183-192, 2008.

[7] A. Karthikeyan, K. Balamurugan, and A. Kalpana, "The new approach to improve the impact property of coconut fiber reinforced epoxy composites using sodium laulryl sulfate treatment," Journal of Scientific \& Industrial Research, vol. 72, no. 2, pp. 132-136, 2013.

[8] P. Noorunnisa Khanam, H. P. S. Abdul Khalil, G. Ramachandra Reddy, and S. Venkata Naidu, "Tensile, flexural and chemical resistance properties of sisal fibre reinforced polymer composites: effect of fibre surface treatment," Journal of Polymers and the Environment, vol. 19, no. 1, pp. 115-119, 2011.

[9] V. G. Akash, K. V. SreenivasRao, C. B. Prasad, and Prabilsonkhadka, "Comparative evaluation of mechanical and water absorption properties of pure epoxy resin, coir fiber/epoxy resin and hemp fiber/epoxy resin composite," International Journal of Applied Engineering Research, vol. 10, no. 55, 2015.

[10] X. Li, L. G. Tabil, and S. Panigrahi, "Chemical treatments of natural fiber for use in natural fiber-reinforced composites: a review," Journal of Polymers and the Environment, vol. 15, no. 1, pp. 25-33, 2007.

[11] N. Venkateshwaran, A. ElayaPerumal, and M. Jagatheeshwaran, "Effect of fiber length and fiber content on mechanical properties of banana fiber/epoxy composite," Journal of Reinforced Plastics and Composites, vol. 30, no. 19, pp. 1621-1627, 2011.
[12] N. Venkateshwaran, A. ElayaPerumal, A. Alavudeen, and M. Thiruchitrambalam, "Mechanical and water absorption behaviour of banana/sisal reinforced hybrid composites," Materials and Design, vol. 32, no. 7, pp. 4017-4021, 2011.

[13] N. Venkateshwaran and A. Elayaperumal, "Banana fiber reinforced polymer composites-a review," Journal of Reinforced Plastics and Composites, vol. 29, no. 15, pp. 2387-2396, 2010.

[14] S. K. Garkhail, Composites based on natural fibres and thermoplastic matrices [Ph.D. dissertation], University of London, London, UK, 2002.

[15] O. Faruk, A. K. Bledzki, H.-P. Fink, and M. Sain, "Progress report on natural fiber reinforced composites," Macromolecular Materials and Engineering, vol. 299, no. 1, pp. 9-26, 2014.

[16] B.-H. Lee, H.-J. Kim, and W.-R. Yu, "Fabrication of long and discontinuous natural fiber reinforced polypropylene biocomposites and their mechanical properties," Fibers and Polymers, vol. 10, no. 1, pp. 83-90, 2009.

[17] O. Faruk, A. K. Bledzki, H.-P. Fink, and M. Sain, "Biocomposites reinforced with natural fibers: 2000-2010," Progress in Polymer Science, vol. 37, no. 11, pp. 1552-1596, 2012.

[18] H. Ku, H. Wang, N. Pattarachaiyakoop, and M. Trada, "A review on the tensile properties of natural fiber reinforced polymer composites," Composites Part B: Engineering, vol. 42, no. 4, pp. 856-873, 2011.

[19] M. A. Khan, M. M. Hassan, R. Taslima, and A. I. Mustafa, "Role of pretreatment with potassium permanganate and urea on mechanical and degradable properties of photo cured coir fiber with 1, 6 hexanediol diacrylate," Journal of Applied Polymer Science, vol. 100, pp. 4361-4368, 2006.

[20] Y. $\mathrm{Li}, \mathrm{C} . \mathrm{Hu}$, and $\mathrm{Y}$. Yu, "Interfacial studies of sisal fiber reinforced high density polyethylene (HDPE) composites," Composites Part A: Applied Science and Manufacturing, vol. 39, no. 4, pp. 570-578, 2008.

[21] B. K. Goriparthi, K. N. S. Suman, and N. Mohan Rao, "Effect of fiber surface treatments on mechanical and abrasive wear performance of polylactide/jute composites," Composites Part A: Applied Science and Manufacturing, vol. 43, no. 10, pp. 18001808, 2012.

[22] S. M. Luz, J. Del Tio, G. J. M. Rocha, A. R. Gonçalves, and A. P. Del'Arco Jr., "Cellulose and cellulignin from sugarcane bagasse reinforced polypropylene composites: effect of acetylation on mechanical and thermal properties," Composites Part A: Applied Science and Manufacturing, vol. 39, no. 9, pp. 1362-1369, 2008.

[23] M. Pracella, D. Chionna, I. Anguillesi, Z. Kulinski, and E. Piorkowska, "Functionalization, compatibilization and properties of polypropylene composites with Hemp fibres," Composites Science and Technology, vol. 66, no. 13, pp. 2218-2230, 2006.

[24] A. K. Bledzki, A. A. Mamun, A. Jaszkiewicz, and K. Erdmann, "Polypropylene composites with enzyme modified abaca fibre," Composites Science and Technology, vol. 70, no. 5, pp. 854-860, 2010.

[25] M. P. Sepe, “Thermal analysis of polymers," Rapra Review Reports, vol. 8, no. 11, p. 17, 1997, Report 95.

[26] N. Sgriccia, M. C. Hawley, and M. Misra, "Characterization of natural fiber surfaces and natural fiber composites," Composites Part A: Applied Science and Manufacturing, vol. 39, no. 10, pp. 1632-1637, 2008.

[27] J. Biagiotti, D. Puglia, L. Torre et al., "A systematic investigation on the influence of the chemical treatment of natural fibers on 
the properties of their polymer matrix composites," Polymer Composites, vol. 25, no. 5, pp. 470-479, 2004.

[28] W. Liu, A. K. Mohanty, L. T. Drzal, P. Askel, and M. Misra, "Effects of alkali treatment on the structure, morphology and thermal properties of native grass fibers as reinforcements for polymer matrix composites," Journal of Materials Science, vol. 39, no. 3, pp. 1051-1054, 2004. 

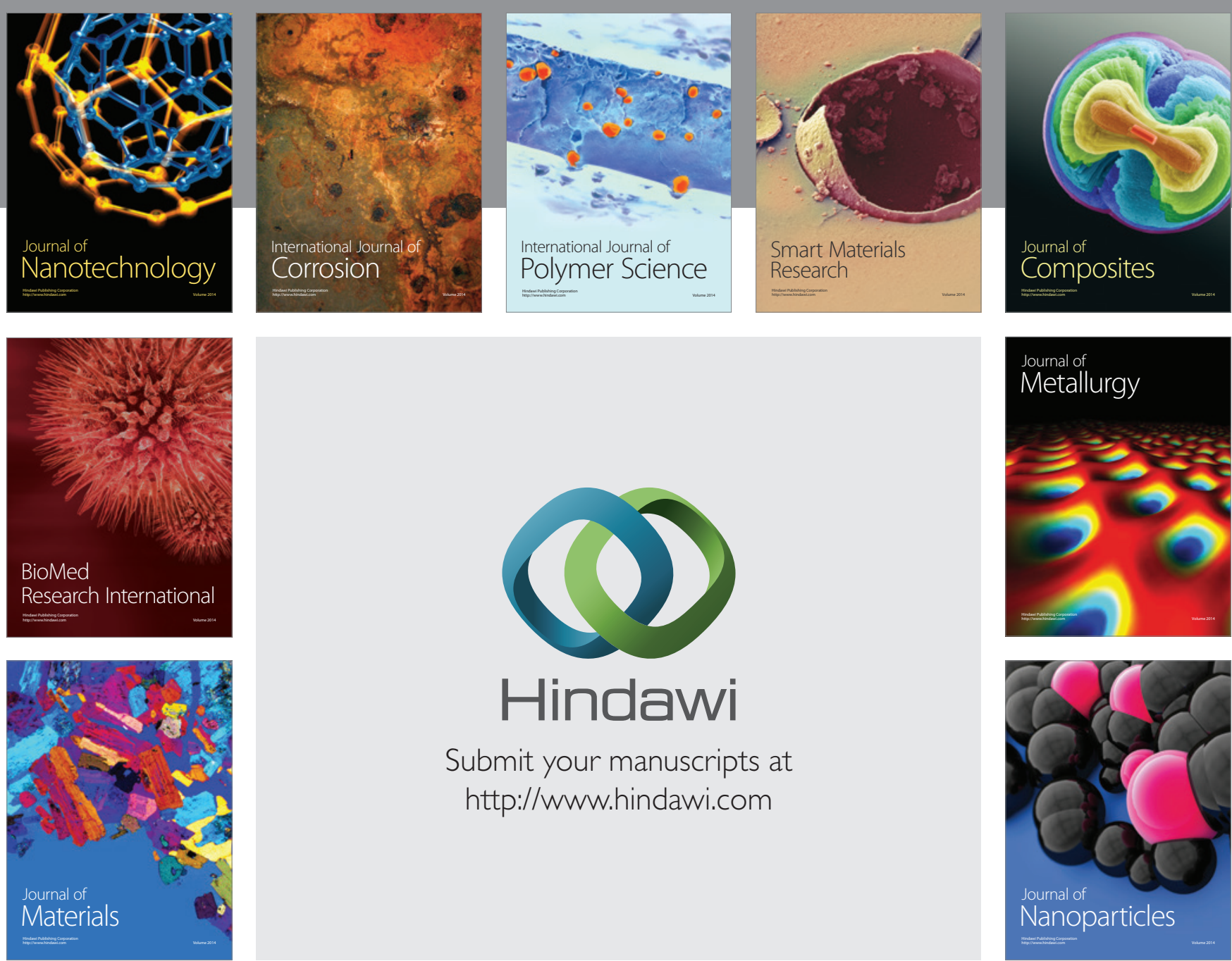

\section{Hindawi}

Submit your manuscripts at

http://www.hindawi.com

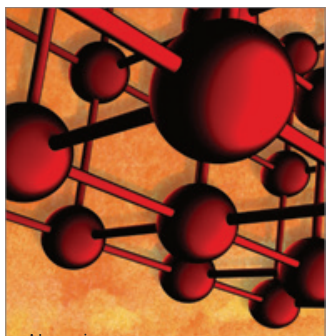

Materials Science and Engineering
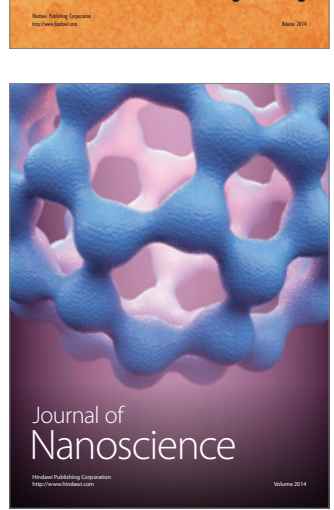
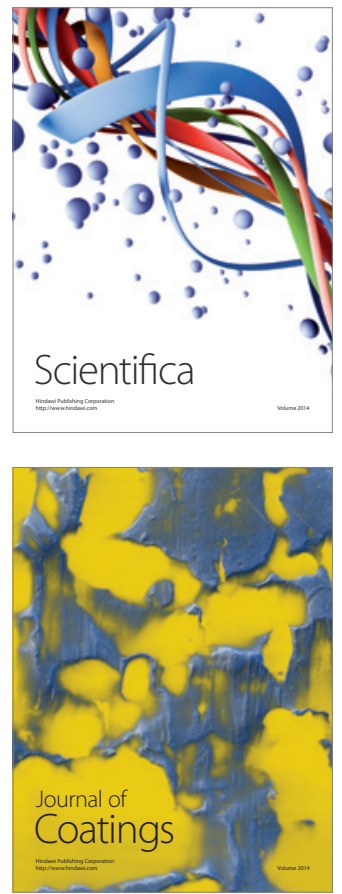
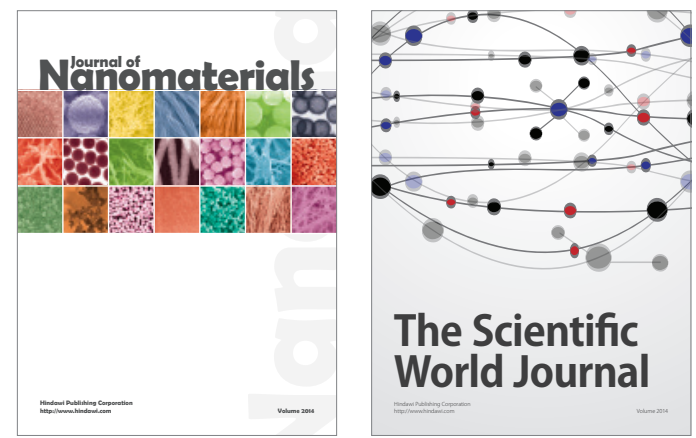

The Scientific World Journal
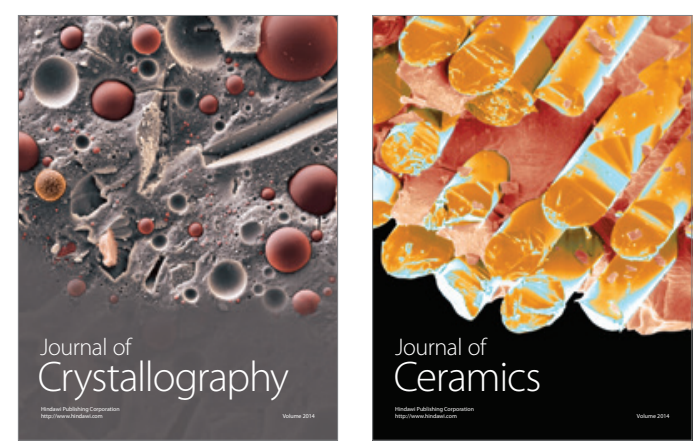
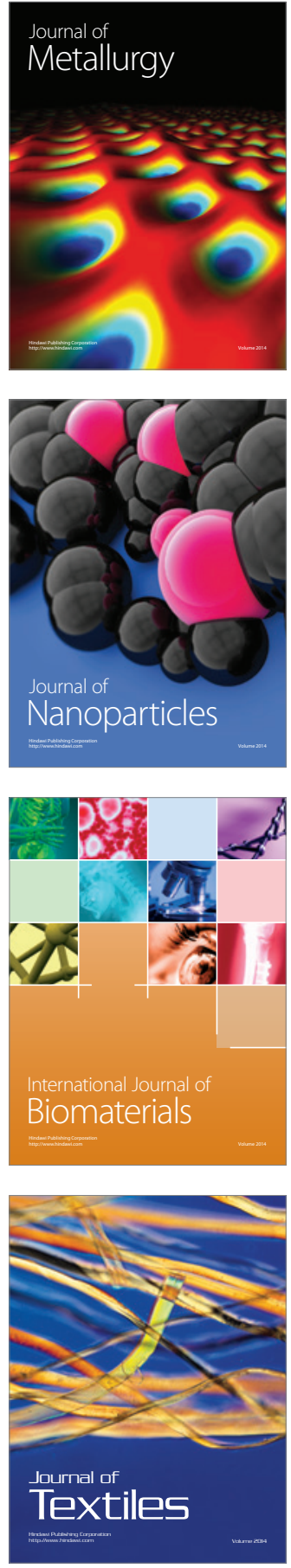